\title{
Supressão da resposta imunitária humoral causada pela citrinina
}

[Humoral immunosupression caused by citrinin]

\author{
C.A. Carvalho, B.C.T.M. Fernandes, R.B. Freire* \\ Instituto de Biologia - Universidade Federal Rural do Rio de Janeiro \\ BR $465 \mathrm{~km} 7$ \\ 23890-000 - Seropédica, RJ
}

\begin{abstract}
RESUMO
Avaliou-se o efeito imunotóxico causado por exposição a baixas doses de citrinina $\left(2,5 \mathrm{mg} \mathrm{kg}^{-1}\right) \mathrm{em}^{-}$ camundongos albinos expostos à micotoxina antes $(n=15)$, durante $(n=15)$ e após $(n=15)$ a imunização com antígeno inerte, representado por eritrócitos de carneiro - sheep red blood cells (SRBC). Quinze camundongos foram usados como controle (não intoxicados). Sete dias após o tratamento, os animais foram sangrados e os títulos de anticorpos anti-SRBC e de complemento foram determinados. A citrinina diminuiu os títulos de anticorpos primários em todos os grupos intoxicados. A intoxicação antes e após a imunização provocou diminuição em $87,5 \%$ nos títulos médios de anticorpos específicos. A exposição simultânea à imunização gerou diminuição de $75 \%$. Houve acentuada redução nos níveis de complemento circulante, detectada nos animais previamente intoxicados $(93,8 \%)$, ou intoxicados juntamente com a imunização $(87,5 \%)$.
\end{abstract}

Palavras-chave: citrinina, micotoxinas, imunossupressão, cumarinas

\begin{abstract}
The immunotoxic effect caused by citrinin was evaluated in albino mice exposed to a single dose of $2.5 \mathrm{mg} \cdot \mathrm{kg}^{-1}$ before $(n=15)$, concomitantly $(n=15)$ and after $(n=15)$ immunization with an inert antigen represented by sheep red blood cells (SRBC). The animals were bleed seven days following the mycotoxin exposure for antibodies anti-SRBC and complement titration and compared to results obtained from nonexposed controls $(n=15)$. It was detected a decreasing antibodies titration in all the intoxicated animals. Those animals that received citrinin before and after SRBC sensitization equally presented a lowering of $87.5 \%$ on the primary antibodies level. The exposure to the mycotoxin simultaneously to the SRBC sensitization caused a decrease equivalent to $75 \%$. A remarkable effect was also demonstrated for the circulating complement in both groups of animals, with a decrease of $87.5 \%$ on those intoxicated before and of $93.8 \%$ on those treated concomitantly to the SRBC sensitization.
\end{abstract}

Keywords: citrinin, mycotoxins, immunosuppression, coumarins

\section{INTRODUÇ̃̃O}

A citrinina é um subproduto metabólico de origem cumarínica, oriundo do crescimento de várias espécies de fungos dos gêneros
Penicillium e Aspergillus. Ela e outras micotoxinas são produzidas durante $\mathrm{o}$ desenvolvimento fúngico em grãos, alimentos processados e produtos alimentícios, oriundos ou não do processamento e da manipulação em

Recebido para publicação em 15 de outubro de 2003

Recebido para publicação, após modificações, em 1 de abril de 2004

*Autor para correspondência (corresponding author)

E-mail: rbfreire@ufrrj.br 
citricultura. O consumo de baixa concentração, por animais sensíveis às micotoxinas, pode conduzir à morte dentro de poucas horas. $\mathrm{O}$ mais comum é a ocorrência de intoxicações que variam de agudas a crônicas, afetando, principalmente os animais criados sob regime de confinamento, tais como aves e suínos.

Em geral, a saúde e a produtividade de animais alimentados com produtos contaminados com concentrações subletais de citrinina são seriamente prejudicados. A micotoxina modula a resposta inflamatória em aves e mamíferos, interferindo em processos de digestão e secreção de mediadores a partir de células imunocompetentes (Herzog-Soares, 1994; Souza et al., 1997). Uma vez que os componentes do sistema complemento são secretados por fagócitos durante os processos inflamatórios, os efeitos comumente atribuídos às diversas micotoxinas sobre a síntese protéica podem acarretar deficiências na sua produção, permitindo, assim, a permanência de agentes infecciosos e a ocorrência de infecções oportunistas (Corrier, 1991; Freire et al., 1996).

Acredita-se que a ação supressiva de micotoxinas sobre a resposta inflamatória tenha efeito bastante significativo sobre a resposta adaptativa humoral em mamíferos diversos (Freire et al., 1996). A citrinina foi caracterizada por não afetar a produção de anticorpos (Reddy et al., 1988; Corrier, 1991), a despeito de causar modificações drásticas nos níveis de leucócitos circulantes, com conseqüente leucopenia (Reddy et al., 1988; Herzog-Soares, 1997). Recentemente, verificouse que a citrinina também pode estar associada à indução de blastogênese linfocitária (Souza et al., 1999). O objetivo deste trabalho foi determinar o efeito da intoxicação sub-clínica por citrinina sobre a atividade do sistema complemento e sobre a resposta imune humoral para antígenos inertes, durante diferentes fases de imunização, utilizando-se camundongos albinos (Swiss Webstern) como modelo experimental.

\section{MATERIAL E MÉTODOS}

Usou-se citrinina purificada em estado cristalino, fornecida pelo Centro de Micologia e Micotoxicologia (CMM)-Convênio Sanidade Animal UFRRJ/EMBRAPA. A micotoxina foi solubilizada em tampão carbonato-bicarbonato (26 partes de uma solução contendo $21,2 \mathrm{~g}$ de $\mathrm{Na}_{2} \mathrm{CO}_{3}$ em $1000 \mathrm{ml}$ adicionados a 74 partes de uma solução contendo $16,8 \mathrm{~g}$ de $\mathrm{NaHCO}_{3}$ para $1000 \mathrm{ml}, \mathrm{pH} 9,5)$ e, posteriormente, diluída em $0,1 \mathrm{M}$ de salina tamponada com fosfatos (PBS $0,1 \mathrm{M}-8,0 \mathrm{~g}$ de $\mathrm{NaCl} ; 0,2 \mathrm{~g}$ de $\mathrm{KCl} ; 1,2 \mathrm{~g}$ de $\mathrm{Na}_{2} \mathrm{HPO}_{4} ; 0,2 \mathrm{~g}$ de $\mathrm{KH}_{2} \mathrm{PO}_{4} ; \mathrm{H}_{2} \mathrm{O}$ qsp $1000 \mathrm{ml}$, $\mathrm{pH} \mathrm{7,2).}$

Trinta camundongos suíços albinos, machos, com duas semanas de vida, com peso médio de 25 gramas, fornecidos pelo biotério central da Universidade Federal Fluminense, foram mantidos em caixas apropriadas e alimentados com ração comercial livre de micotoxinas e água potável ad libitum. Os animais foram imunizados de acordo com metodologia clássica, mediante inoculação intraperitoneal de $1 \mathrm{ml}$ de uma suspensão de eritrócitos de carneiro (sheep red blood cells - SRBC) a 2,5\% em PBS a $0,1 \mathrm{M}, \mathrm{pH}$ 7,2. Grupos de cinco animais foram sensibilizados antes, durante e após o tratamento com citrinina, e estudados comparativamente a três grupos de cinco animais-controle não tratados com micotoxinas. Todos os experimentos foram realizados com três repetições. Após intervalo de sete dias, obtiveram-se amostras de soro dos animais a partir da sangria na veia mamária esquerda, tal como descrito por Hudson e Hay (1989). Os soros foram agrupados de acordo com a sensibilização por SRBC e com o tratamento com citrinina, e divididos em dois lotes, o primeiro relativo às amostras de soro inativadas pela incubação a $56 \pm 1^{\circ} \mathrm{C}$, durante 30 minutos, e o segundo lote constituído pelas amostras não inativadas (soro fresco). Os diferentes agrupamentos e seus respectivos lotes foram acondicionados em frascos apropriados, adicionados de $0,01 \%$ de timerosal e mantidos a $-20 \pm 1^{\circ} \mathrm{C}$, até o momento de uso. Os camundongos foram experimentalmente tratados com uma dose equivalente a $2,8 \%$ da $\mathrm{DL}_{50}$ de $89 \mathrm{mg} / \mathrm{kg}$, anteriormente estabelecida para essa espécie animal (Terse et al., 1993). A micotoxina foi administrada intraperitonealmente, na proporção de $2,5 \mathrm{mg} / \mathrm{kg}$, a grupos de cinco animais, excetuando-se os grupos-controle, que receberam somente o veículo (PBS, 0,1M, $\mathrm{pH} \mathrm{7,2).}$ 
Os níveis séricos de complemento foram avaliados utilizando-se o soro fresco, não inativado, recém obtido pela exsangüinação dos animais (Hudson e Hay, 1989). As diferentes amostras de soro de cada agrupamento experimental foram diluídas serialmente, de 1:2 até 1:4096, em microplacas de sorologia. Sobre as amostras de soro diluídas, foram adicionadas $25 \mu \mathrm{l}$ de SRBC a $2,5 \%$ e $25 \mu \mathrm{l}$ de duas unidades líticas de hemolisina de camundongos SW, antiSRBC, preparadas no setor de imunologia do laboratório de toxicologia ambiental (Departamento de Biologia Animal DBA/Universidade Federal Rural do Rio de Janeiro). Foram feitos controles da hemolisina, dos SRBC e dos soros dos camundongos testados, para garantir que não ocorreriam hemólises por motivos distintos à fixação do complemento pelo sistema hemolítico (SRBC hemolisina). As microplacas foram incubadas a $37 \pm 1^{\circ} \mathrm{C}$, durante 40 minutos, e analisadas quanto ao título médio de complemento existente em cada agrupamento de soros. Considerou-se como título a maior diluição do soro-teste capaz de causar hemólise frente ao sistema hemolítico.

A titulação dos anticorpos anti-SRBC, produzidos pelo primocontato dos diferentes agrupamentos uma semana antes, foi realizada por meio do método clássico de fixação do complemento (Hudson e Hay, 1989), visto que eles seriam, em sua maioria, pertencentes à classe IgM. Para tanto, procedeu-se ao ensaio utilizando-se como fonte de hemolisina os soros inativados obtidos de cada grupo. Uma vez que o tratamento a $56 \pm 1^{\circ} \mathrm{C}$ elimina a atividade complementar do soro, acrescentou-se a cada diluição dos diferentes agrupamentos, $25 \mu 1$ de SRBC a $2,5 \%$ e $25 \mu 1$ de uma solução com duas unidades de complemento de soro fresco de coelho, preparadas no laboratório de imunotoxicologia do DBA da UFRRJ. Foram feitos controles do complemento dos eritrócitos de carneiro e dos soros dos camundongos a serem testados, para garantir que não ocorreriam hemólises por motivos distintos à fixação do complemento, pela existência de anticorpos fixadores do complemento nos soros dos animais. As microplacas foram incubadas à $37 \pm 1^{\circ} \mathrm{C}$, durante 40 minutos, e analisadas quanto ao título médio de anticorpos existentes em cada agrupamento de soros. Considerou-se como título a maior diluição do soro-teste capaz de causar hemólise frente ao complemento.

Usou-se o teste de Tuckey para a comparação de médias, conforme Souza et al. (1999).

\section{RESULTADOS E DISCUSSÃO}

A freqüente ocorrência de intoxicações naturais causadas por micotoxinas cumarínicas, tais como a citrinina e a ocratoxina, suscita discussão a respeito da intoxicação subclínica ocasionada por essas micotoxinas. $\mathrm{Na}$ realidade, pouco se conhece sobre a atividade imunomodulatória desses compostos. Reddy et al. (1988) foram os primeiros investigadores a detectar alterações imunitárias em animais expostos à citrinina, identificando uma linfopenia induzida por exposições à citrinina, e sugeriram que ela atuaria também como uma toxina imunoestimuladora. Embora tenha sido capaz de induzir nefropatias em concentrações elevadas, em dosagens menores seria um imunoestimulador, a despeito de reduzir a quantidade de linfócitos circulantes. Segundo Corrier (1991), a citrinina não causaria efeitos imunológicos importantes em aves ou mamíferos. No presente trabalho, procurou-se identificar a ação imunomodulatória decorrente da exposição de camundongos albinos à baixas doses de citrinina, uma vez que, em experimentos anteriores, foram observados efeitos antiinflamatórios marcantes, causados por pequenas concentrações dessa micotoxina (Herzog-Soares, 1994; Souza et al., 1999).

Os títulos médios de anticorpos específicos caíram $87,5 \%$ nos animais expostos à citrinina antes ou depois da imunização com antígeno inerte. A exposição simultânea à imunização gerou diminuição de 75\%. Houve, também, acentuada redução nos níveis de complemento circulante, detectada nos animais previamente intoxicados $(93,8 \%)$, ou intoxicados juntamente com a imunização $(87,5 \%)$. O título médio de anticorpos circulantes anti-eritrócitos de carneiro foi de 1:64 nos indivíduos expostos à citrinina antes ou após a imunização, 1:128 para aqueles que receberam o antígeno inerte concomitantemente à exposição a micotoxina e 1:512 para os animais pertencentes ao grupocontrole (não intoxicado) (Fig. 1). O título médio 
de complemento detectado foi de 1:256 nos animais previamente expostos, 1:512 nos intoxicados ao mesmo tempo em que se administrou o antígeno e 1:4096 nos intoxicados após imunização, e nos do grupo-controle (Fig. 2). A não interferência sobre a resposta adaptativa, quando a micotoxina foi administrada juntamente com o antígeno inerte, sugere a formação de complexos capazes de inibir a ação dessa micromolécula tóxica, conforme sugerido por Freire (1996) e Souza et al. (1999).

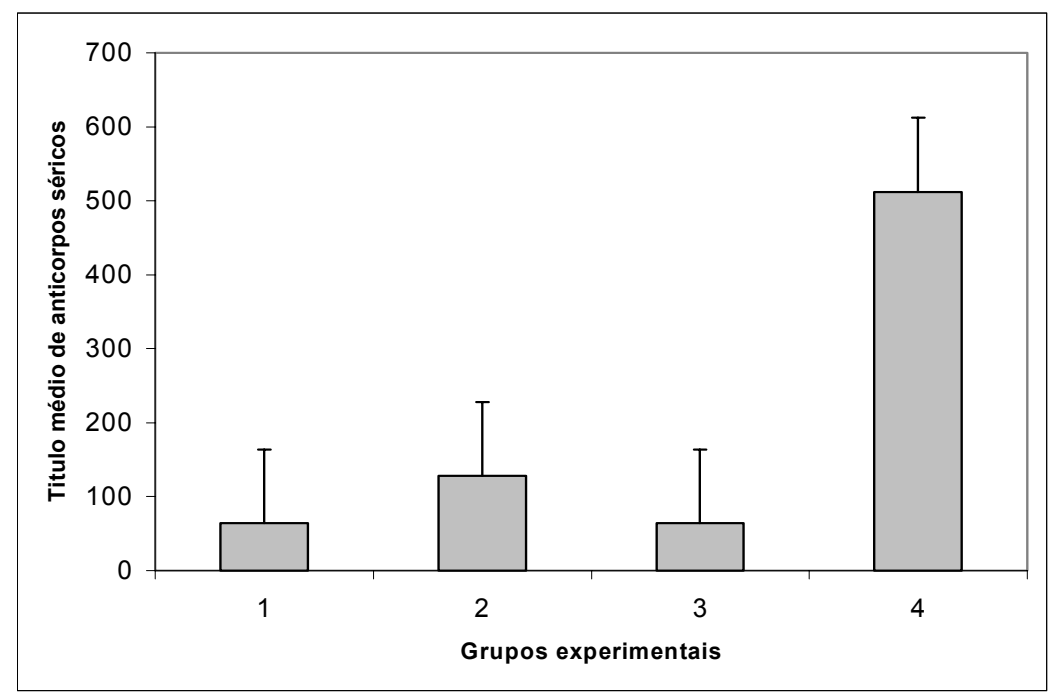

Figura 1. Título médio de anticorpos antieritrócitos de carneiro (SRBC) detectados em grupos de camundongos suiço-albinos ( $\mathrm{SW}$ ) tratados com 2,5 mg. $\mathrm{kg}^{-1}$ de citrinina antes (1); concomitantemente (2) e após sensibilização (3) com $\mathrm{SRBC}$ a $2,5 \%$, em relação a um grupo controle não intoxicado (4). Os resultados são oriundos de três repetições para cada grupo de cinco animais e representam a média \pm $\mathrm{EPM}$, com $\mathrm{P}<0,01$.

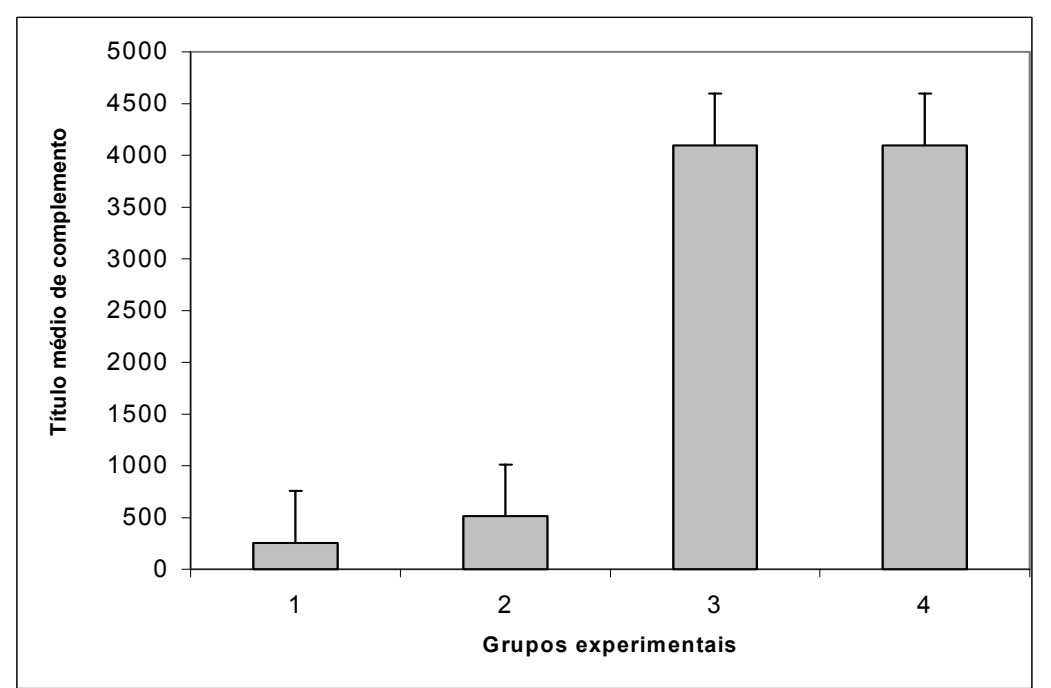

Figura 2. Título médio de complemento detectado em grupos de camundongos suiço-albinos (SW) tratados com 2,5mg. $\mathrm{kg}^{-1}$ de citrinina antes (1); concomitantemente (2) e após sensibilização (3) com SRBC a 2,5\%, em relação a um grupo controle não intoxicado (4). Os resultados são oriundos de três repetições para cada grupo de cinco animais e representam a média $\pm \mathrm{EPM}$, com $\mathrm{P}<0,01$. 
Os efeitos contundentes sobre o funcionamento do sistema complemento foram semelhantes aos observados em trabalhos anteriores, nos quais se detectou uma potente inibição na produção de citocinas e interferon para determinados grupos de micotoxinas, tais como fumonisinas e tricotecenos (Gerberick e Sorenson, 1983; Hughes et al., 1989; Qureshi e Hagler, 1992). Souza et al. (1997) observaram que a supressão total da fagocitose, induzida por citrinina, tanto in vivo quanto in vitro, seria o resultado de um processo de esgotamento metabólico induzido por exposição a baixas doses de micotoxina. Ensaios realizados com a toxina $\mathrm{T} 2$ relatam a inibição na biossíntese de fibronectina como sendo a principal causa de efeitos inibitórios na fagocitose, porque afetaria, de modo direto, a ingestão de partículas e a formação de fagossomas (Gerberick e Sorenson, 1983). Assim, a interferência na resposta adaptativa estaria diretamente relacionada à incapacidade de processamento e apresentação dos antígenos disponibilizados para o sistema imunitário dos camundongos expostos a citrinina (Freire, 1996; Freire et al., 1996). Os níveis séricos mais baixos de complemento, observados nos animais sensibilizados após exposição à citrinina, indicam que esta tende a mostrar-se mais imunotóxica para animais neonatos que ainda não foram sensibilizados pelos diferentes patógenos do ambiente. $\mathrm{O}$ fato de ter havido significativa diminuição dos níveis de anticorpos dos animais intoxicados após a imunização sem, contudo, ocorrer diminuição significativa nos níveis de complemento, sugere mecanismos diferenciados, relacionados à síntese de anticorpos. A inibição da síntese macromolecular induzida por essa micotoxina foi observada in vitro por Braunberg et al. (1992), que demonstraram que as micotoxinas citrinina e ocratoxina podem induzir pronunciada inibição dessa atividade, dependendo do tipo celular envolvido, das concentrações de micotoxinas e da espécie animal estudada. Nesse experimento, no entanto, os autores concluíram que a citrinina, em concentrações acima de $0,25 \mathrm{mg} \cdot \mathrm{mL}^{-1} \cdot 10^{-6}$ células, seria capaz de produzir inibição completa da síntese de proteínas prejudicando, dentre outras funções fisiológicas importantes, a resposta imune.

A queda no título de anticorpos anti-eritrócitos de carneiro (anti SRBC) detectada nos animais expostos à citrinina assemelhou-se àquela observada por Hughes et al. (1989) em camundongos expostos aos diversos compostos macrocíclicos do grupo dos tricotecenos, atingindo até $73 \%$ de redução na produção primária $(\operatorname{IgM})$, e de $10 \%$ na produção secundária (IgG). Reddy et al. (1988) demonstraram que a produção primária de anticorpos foi deprimida nos animais expostos a baixas doses de citrinina, aumentando, porém, quando os animais foram intoxicados com doses mais elevadas. Nesse ensaio, os animais foram sensibilizados após duas semanas de exposição crônica e contínua à citrinina, em doses que variaram de 0,12 a $3,0 \mathrm{mg} \cdot \mathrm{kg}^{-1}$. A dose de $2,5 \mathrm{mg} \cdot \mathrm{kg}^{-1}$ utilizada no presente trabalho originou resultados semelhantes aos relacionados às menores dosagens de citrinina empregadas por Reddy et al. (1988). A semelhança observada sugere que, uma vez que no presente trabalho utilizou-se uma dose que se aproxima da maior dose utilizada por esses autores, ocorreu detoxicação da citrinina inoculada, que tornou os níveis de micotoxina baixos o suficiente para produzirem diminuição da produção de anticorpos, tal como ocorre em intoxicações crônicas induzidas por pequenas doses de citrinina. Experimentos anteriores assinalam a ocorrência de apoptose induzida por doses mais elevadas de citrinina, além de estimulação, caracterizada por proliferação inespecífica de linfócitos, porém mais relacionada a linfócitos $\mathrm{T}$ (Hughes et al., 1989; Freire et al., 1996; Carvalho et al., 1997; Souza et al., 1999). O efeito imunoestimulante provocado por doses mais elevadas de citrinina, embora aparentemente controvertido, reforça a idéia de que essa micotoxina apresente diferentes mecanismos de atuação, relacionados à biodisponibilidade e à capacidade de detoxicação (maturidade) do organismo animal exposto.

\section{CONCLUSÕES}

Conclui-se que a citrinina é imunotóxica para animais jovens, comprometendo tanto a resposta humoral adaptativa como a resposta natural, quando assimilada em baixas concentrações, mesmo após uma única exposição. Assim, os animais em idade de vacinação representam um grupo de risco para o qual deve-se dar mais atenção, especialmente porque essa micotoxina 
pode comprometer sua capacidade de resposta às diferentes vacinas, sem sintomas clínicos indicativos de imunossupressão ou intoxicação.

\section{AGRADECIMENTOS}

Este trabalho foi realizado sob orientação do Professor Ronald B. Freire, com apoio do CNPq - Projeto n ${ }^{\mathrm{o}}$ 305370088-0.

\section{REFERÊNCIAS BIBLIOGRÁFICAS}

BRAUNBERG, R.C.; GANTT, O.; BARTON, C. et al. In vitro effects of the nephrotoxins Ochratoxin A and citrinin upon biochemical function of porcine kidney. Arch. Environm. Contam. Toxicol., v.22, p.464-470, 1992.

CARVALHO, C.A.; RIBEIRO, C.S.; PEREIRA, A.A. et al. Citrinin: modulation chicken's lymphocyte blastogenesis. In: LATINOAMERICAN MYCOTOXICOLOGY CONGRESS, 2., 1997, Maracay. Proceedings... Maracay, 1997. Resumo.

CORRIER, D.E. Mycotoxicosis: mechanisms of immunossupression. Vet. Immunol. Immunopathol., v.30, p.73-87, 1991.

FREIRE, R.B. Micotoxinas e resposta imune. In: CRUZ, L.C.H. (Ed.) Micotoxinas: perspectiva latinoamericana. Rio de Janeiro: Seropédica, 1996. p.141-148.

FREIRE, R.B.; SOUZA, C.C.; CRUZ, L.C.H. Humoral immunoresponse discontinuance caused by citrinin. In: INTERNATIONAL IUPAC SYMPOSIUM ON MYCOTOXINS AND PHYCOTOXINS, 1996, Havana. Anais...Havana, 1996. Resumo.

GERBERICK, G.F.; SORENSON, W.G. Toxicity of $\mathrm{t} 2$ toxin a Fusarium mycotoxin to alveolar macrophages in vitro. Environm. Rev., v.32, p.269-285, 1983.
HERZOG-SOARES, J.D.A. Efeito regulador da citrinina sobre macrófagos de galinhas da raça Leghorn. 1994. 87f. Dissertação (Mestrado em Microbiologia Veterinária) - Universidade Federal Rural do Rio de Janeiro, Seropédica, RJ.

HERZOG-SOARES, J.D.A. Relação parasitohospedeiro: ação de subdoses de micotoxinas sobre a resposta imunitária em aves e mamíferos para coccídeas. 1997. 145f. Tese (Doutorado em Microbiologia Veterinária) - Universidade Federal Rural do Rio de Janeiro, Seropédica, RJ.

HUDSON, L.; HAY, F. Complement in practical immunology. 3.ed. Blackwell, 1989. p.264-280.

HUGHES, B.J.; HIESH, G.C.; JARVIS, B.B. et al. Effects of macrociclic thrichothecene mycotoxins on the immune system. Arch. Environm. Contam. Toxicol., v.18, p.388-395, 1989.

QURESHI, M.A.; HAGLER Jr., W.M. Effect of Fumonisin B1 exposure on chicken macrophage fuctions in vitro. Poult. Sci., v.71, p.104-112, 1992.

REDDY, R.V.; TAYLOR, M.J.; SHARMA, R.P. Evaluation of citrinin toxicity on the immune functions of mice. J. Food Protec., v.51, p.32-36, 1988.

SOUZA, M.M.S.; FREIRE, R.B.; CARVALHO, C.A. Avaliação da ação imunomodulatória da citrinina através da estimulação da blastogênese linfocitária. Rev. Bras. Med. Vet., v.21, p.69-71, 1999.

SOUZA, M.M.S.; FREIRE, R.B.; SOUZA, C.C. et al. Supressão da resposta inflamatória por exposição a citrinina: proposta de mecanismo de ação. Rev. Bras. Med. Vet., v.19, p.28-30, 1997.

TERSE, P.S.; MADHYASTHA, M.S.; ZUROVAC, O. et al. Comparison of in vitro and in vivo biological activity of mycotoxins. Toxicon, v.31, p.913-919, 1993. 